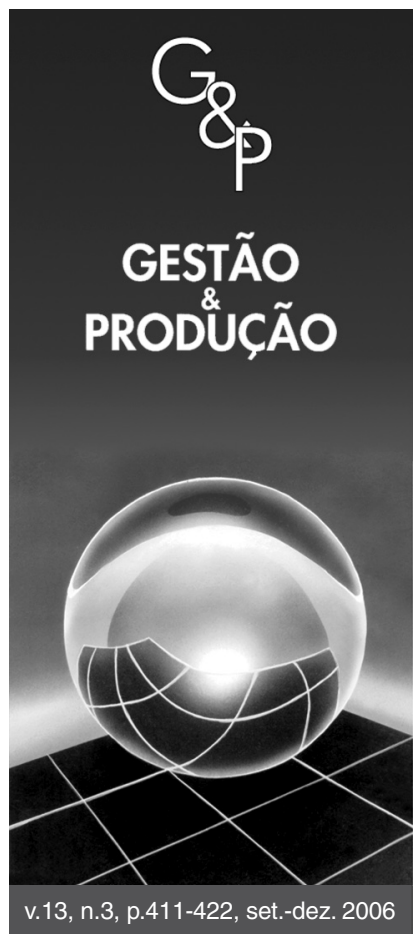

\title{
METODOLOGIA DE CHECKLAND APLICADA À IMPLEMENTAÇÃO DA PRODUÇÃO MAIS LIMPA EM SERVIÇOS
}

\author{
Gisele Cristina Sena da Silva \\ Denise Dumke de Medeiros
}

Grupo de Pesquisa PLANASP, Departamento de Engenharia de Produção, Universidade Federal de Pernambuco, Centro de Tecnologia, Av. Acadêmico Hélio Ramos, s/n, $5^{\circ}$ andar, Bloco Administrativo, Cidade Universitária, CEP 50740-530, Recife, PE, Brasil, e-mails: gsena@ufpe.br, ddm@ufpe.br

Resumo

O programa de Produção Mais Limpa tem sido aplicado com sucesso na indústria manufatureira, entretanto, esta ferramenta está longe de ser adotada por empresas de prestação de serviço. Este artigo tem como principal contribuição caracterizar o desenvolvimento e a aplicação da Produção Mais Limpa na prestação de serviço, a partir da utilização da Metodologia de Checkland para estruturação de problemas. Essa metodologia objetiva a comparação entre sistema real (como a empresa se encontra hoje) e conceitual (como a empresa iria funcionar se adotasse a Produção Mais Limpa) no sentido de traçar cenários de mudanças e auxiliar os gestores na tomada de decisão sobre adotar ou não adotar este programa.

Palavras-chave: produção mais limpa, desenvolvimento sustentável, sistema de gestão ambiental, prestação de serviço.

\section{Introdução}

No cenário econômico atual, a prestação de serviço está em evidência e já é responsável pela maior parcela da economia global. Com o crescimento do número de empresas prestadoras de serviços, cresce também o número de competidores, fazendo com que seja necessário, para as empresas, melhorar sua eficiência por meio de alternativas que diferenciem seus serviços. Desta forma, o estabelecimento de sistemas de gerenciamento bem organizados pode subsidiar as operações em serviços na melhoria de sua competitividade.

Nas empresas, existe um reconhecimento de que a questão ambiental se tornará muito mais proeminente como um fator que influencia consumidores, leis, grupos de pressão e que o setor de prestação de serviços necessitará mostrar um crescente interesse pela proteção do meio ambiente. Assim, se faz necessário o desenvolvimento de métodos que auxiliem o setor de prestação de serviços a inserir em seus processos o conceito de proteção ao meio ambiente em prol do desenvolvimento sustentável.
A demanda ambiental no setor de prestação de serviços tem sido bem modesta, mas, com o crescimento do setor, ele deverá conhecer seus impactos ambientais e resolvê-los como parte dos problemas ambientais da sociedade. Por este motivo, estas empresas devem se reestruturar para assumir a responsabilidade pela criação de sistemas voltados à preservação de recursos, criando alternativas para um sistema ambiental integrado voltado à renovação do atual modelo de desenvolvimento.

\section{O programa produção mais limpa}

A busca incessante por soluções para problemas ambientais faz com que gestores adotem ferramentas que auxiliem organizações em todo o mundo a agir de forma pró-ativa com relação às questões relacionadas à gestão dos recursos naturais.

Segundo Oliveira Filho (2001), a tecnologia de "fimde-tubo" procura resolver prejuízos ambientais pelo 
controle da poluição no fim do processo produtivo, sem combater a raiz do problema. Em contrapartida, a Produção Mais Limpa $(P+L)$ é uma estratégia tecnológica de caráter permanente que se contrapõe às soluções que objetivam apenas controlar a poluição atuando no final do processo produtivo, como a tecnologia de "fim-de-tubo".

Quando uma solução tecnológica do tipo "fim-detubo" é introduzida em um processo industrial, os impactos ambientais se reduzem imediatamente, porém os aspectos continuam existindo, pois não houve prevenção e sim uma ação de caráter corretivo, elevando normalmente os custos sociais e privados. Além disso, trata-se de uma solução reativa e seletiva, geralmente introduzida para atender aos padrões de emissão ou de qualidade ambiental estabelecidos pela regulamentação governamental (PNUMA, 1993).

Enquanto as técnicas de "fim-de-tubo" representam ações remediativas, que esperam que estes resíduos sejam gerados para, posteriormente, tratá-los, a P + L é uma ação preventiva, que visa evitar ou diminuir a formação do resíduo durante o processo produtivo. Quando uma organização adota os princípios da $\mathrm{P}+\mathrm{L}$, está tentando buscar tecnologias que substituam os tratamentos convencionais de "fim-de-tubo" por modificações no processo produtivo focadas na prevenção e controle de poluição na fonte.

Na Tabela 1, são apresentadas as principais diferenças entre as tecnologias de fim-de-tubo e a $\mathrm{P}+\mathrm{L}$ indicadas pelo Centro Nacional de Tecnologias Limpas - CNTL.

A abordagem da $\mathrm{P}+\mathrm{L}$ privilegia as soluções voltadas para a prevenção e minimização, sugerindo que as empresas atuem na fonte geradora, buscando alternativas para o desenvolvimento de um processo eco-eficiente, resultando na não geração dos resíduos, redução ou reciclagem interna e externa (CNTL, 2003).

Na Figura 1 a seguir, é representada a forma de priorização da atuação segundo a antiga (fim-de-tubo) e nova $(\mathrm{P}+\mathrm{L})$ abordagem.

A antiga abordagem, adotada ainda por muitas organizações, segue o rumo contrário, com a adoção de soluções simplistas que acabam, geralmente, resultando no

Tabela 1. Diferenças entre tecnologias de fim-de-tubo e produção mais limpa.

\begin{tabular}{|c|c|}
\hline Tecnologia de fim-de-tubo & Produção mais limpa \\
\hline Pretende reação. & Pretende ação. \\
\hline $\begin{array}{l}\text { Os resíduos, os efluentes e as } \\
\text { emissões são controlados por } \\
\text { equipamentos de tratamento. }\end{array}$ & $\begin{array}{l}\text { Prevenção da geração de resí- } \\
\text { duos, efluentes e emissões na } \\
\text { fonte. Procura-se evitar ma- } \\
\text { térias-primas potencialmente } \\
\text { tóxicas. }\end{array}$ \\
\hline $\begin{array}{l}\text { Proteção ambiental } \\
\text { para especialistas cc }\end{array}$ & $\begin{array}{l}\text { Proteção ambiental é tarefa } \\
\text { para todos. }\end{array}$ \\
\hline $\begin{array}{l}\text { A proteção ambiental atua de- } \\
\text { pois do desenvolvimento dos } \\
\text { processos e produtos. }\end{array}$ & $\begin{array}{l}\text { A proteção ambiental atua } \\
\text { como uma parte integrante do } \\
\text { design do produto e da enge- } \\
\text { nharia de processo. }\end{array}$ \\
\hline $\begin{array}{l}\text { Os problemas ambientais são } \\
\text { resolvidos a partir de um ponto } \\
\text { de vista tecnológico. }\end{array}$ & $\begin{array}{l}\text { Os problemas ambientais são } \\
\text { resolvidos em todos os níveis e } \\
\text { em todos os campos. }\end{array}$ \\
\hline $\begin{array}{l}\text { Não tem a preocupação com o } \\
\text { uso eficiente de matérias-pri- } \\
\text { mas, água e energia. }\end{array}$ & $\begin{array}{l}\text { Uso eficiente de matérias-pri- } \\
\text { mas, água e energia. }\end{array}$ \\
\hline Leva a custos adicionais. & Ajuda a reduzir custos. \\
\hline
\end{tabular}
Fonte: CNTL (2003).

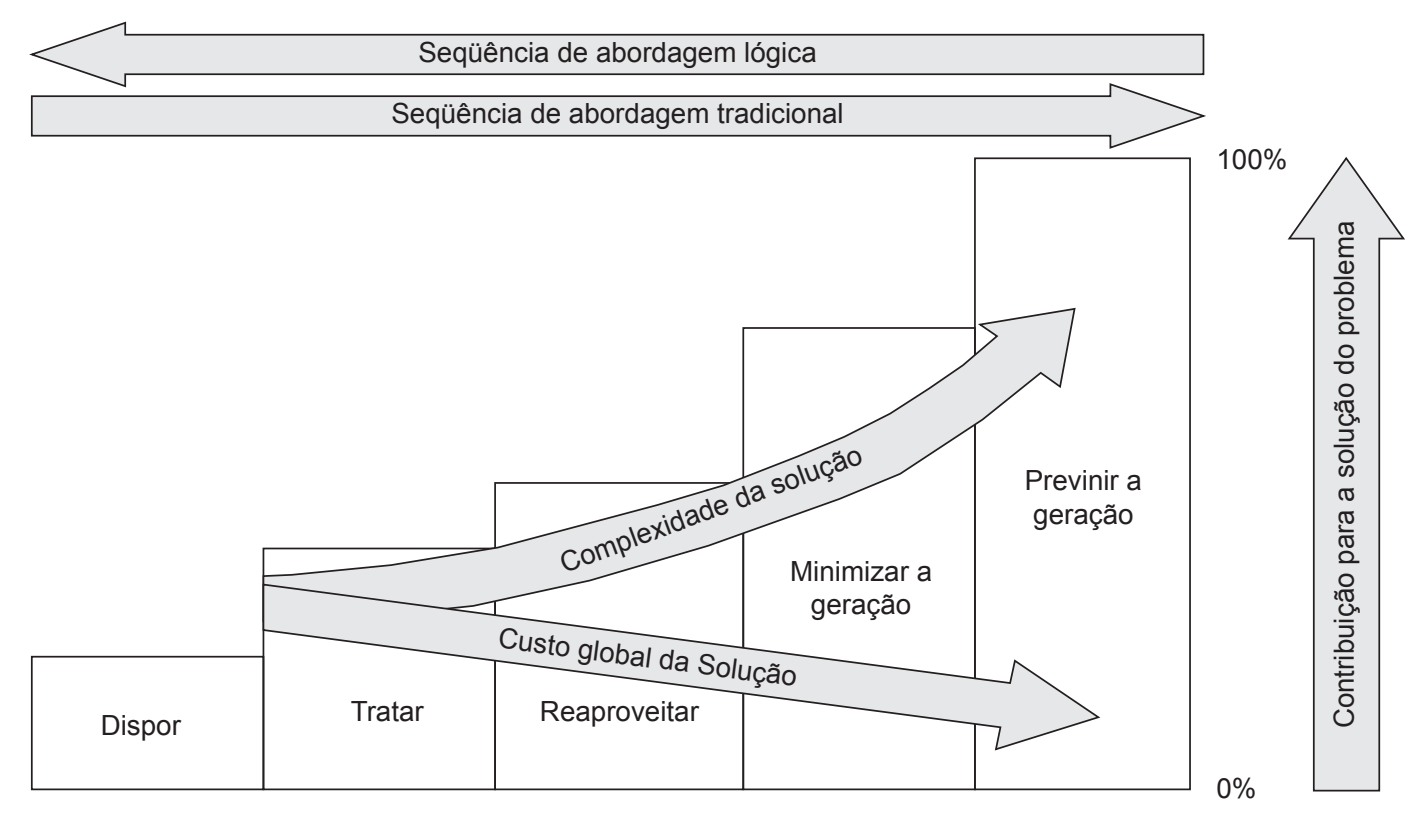

Figura 1. Formas de priorização da nova e da antiga abordagem ambiental. (Fonte: CNTL (2002)). 
aumento dos custos associados ao gerenciamento ambiental. A nova abordagem contribui para a solução de problemas ambientais na fonte, isto é, na prevenção da geração de resíduos, contribuindo de forma muito mais efetiva para a solução do problema ambiental. Apesar de mais complexa, por exigir mudança no processo produtivo e/ou a implementação de novas tecnologias, ela pode permitir uma redução permanente dos custos gerais, incorporando os ganhos ambientais, econômicos e de saúde ocupacional (CNTL, 2003).

A decisão de se adotar um programa de $\mathrm{P}+\mathrm{L}$ depende diretamente da relação custo-benefício que o investimento terá. Um estudo desenvolvido pela CNTL (2003) demonstra que quando há investimentos em $\mathrm{P}+\mathrm{L}$, verifica-se que os custos decrescem significativamente com o tempo, resultado dos benefícios gerados a partir do aumento da eficiência dos processos, do uso eficiente de matérias-primas, água e energia, e da redução de resíduos e emissões gerados.

$\mathrm{A} \mathrm{P}+\mathrm{L}$ pode ser adotada em qualquer setor de atividade e constitui-se de uma análise técnica, econômica e ambiental detalhada do processo produtivo, objetivando a identificação de oportunidades que possibilitem melhorar a eficiência, sem acréscimo de custos para a empresa. A implementação do programa pode envolver um ciclo de estratégias de design em todas as fases do processo, passando a envolver todo o ciclo de vida.

O manual do Centro Nacional de Tecnologias Limpas - CNTL (2003) indica que, antes de se iniciar a implantação da $\mathrm{P}+\mathrm{L}$, é necessária "a pré-sensibilização do público alvo (empresários e gerentes) através de uma visita técnica, fazendo a exposição de casos bem sucedidos, ressaltando seus benefícios econômicos e ambientais".

Segundo a CNTL (2003), a visita técnica visa a obter a participação e comprometimento da alta gerência no processo de implementação da $\mathrm{P}+\mathrm{L}$. A gerência da organização apoiará o programa quando estiver convencida de seus benefícios. Por isso se faz necessária a exposição de casos bem sucedidos, ressaltando as vantagens econômicas, sociais e ambientais de sua implantação. Nesta fase, deve ser enfatizada a necessidade de comprometimento gerencial da empresa, sem o qual não é possível desenvolver o programa. Na Figura 2, são representados os passos que devem ser seguidos para implantação da P + L, segundo a CNTL (2003).

As ações são realizadas em cinco etapas específicas: Planejamento e organização, Diagnóstico, Avaliação, Estudo de Viabilidade e Implementação, monitoramento e controle.

Alguns autores adotam 6 ou 7 etapas para implementação da P + L, outros indicam que dentro dessas etapas, o processo deve ter 18, 19 ou até 20 passos. Para fins deste trabalho, será utilizado o trabalho desenvolvido pelo Centro Nacional de Tecnologias Limpas SENAI/ UNIDO/UNEP (CNTL, 2003), representado na Figura 2 , por este tentar criar um sistema de informação sobre $\mathrm{P}+\mathrm{L}$ nacional, a partir de experiências brasileiras em produção mais limpa em diversos setores produtivos.

\section{Produção mais limpa na prestação de serviços}

Diante do crescimento do número de empresas prestadoras de serviço, o uso de ferramentas que minimizem os impactos ambientais proporcionados por este segmento se faz cada dia mais necessário. Várias pesquisas já foram desenvolvidas para empresas industriais, como os trabalhos de Zwetsloot e Geyer (1996), Boyle (1999), Nissen (1995) e Bass (1995).

Zwetsloot e Geyer (1996) apresentam elementos que podem auxiliar empresas na implementação de programas de P + L com sucesso, sem focar um setor em especial. Boyle (1999) mostra experiências de $\mathrm{P}+\mathrm{L}$ em empresas na Nova Zelândia, identificando os métodos que são necessários para se adotar a $\mathrm{P}+\mathrm{L}$ em pequenas e médias indústrias.

Nissen (1995) desenvolveu em seu trabalho uma metodologia para o desenvolvimento de produtos que não agridam o meio ambiente (eco-products) na indústria manufatureira e Bass (1995) demonstra como colocar em prática o programa de $\mathrm{P}+\mathrm{L}$, por meio de experiências de empresas industriais nos últimos anos. No entanto, conforme abordado anteriormente, pouco foi desenvolvido para a aplicação no setor de prestação de serviços.

A implementação de ferramentas de gestão em empresas prestadoras de serviço deve ser dada de forma diferenciada devido às características inerentes ao setor. Conhecendo as principais características dos serviços, pode-se compreender e determinar as singularidades do seu gerenciamento.

Para Gianesi e Corrêa (1996) e Téboul (1999), a principal dimensão da prestação de serviços que afeta a gestão de suas operações é a ênfase dada à pessoa ou aos equipamentos no processo, seguida pelo grau de contato com o cliente, diferenciado pelo front office (linha de frente), que tem alto grau de contato com o cliente, e o back room (retaguarda) que realiza operação de baixo contato com o cliente. Os outros fatores que influenciam são o grau de participação do cliente no processo, o grau de personalização, o grau de julgamento pessoal dos funcionários e o grau de tangibilidade do serviço.

As características diferenciadoras da prestação de serviços fazem com que seja necessário ter uma visão holística do sistema para incluir o cliente como um participante no processo, isto é, a presença do cliente no processo anula a perspectiva de sistema fechado. Uma visão sistêmica dos processos no setor poderá auxiliar na 


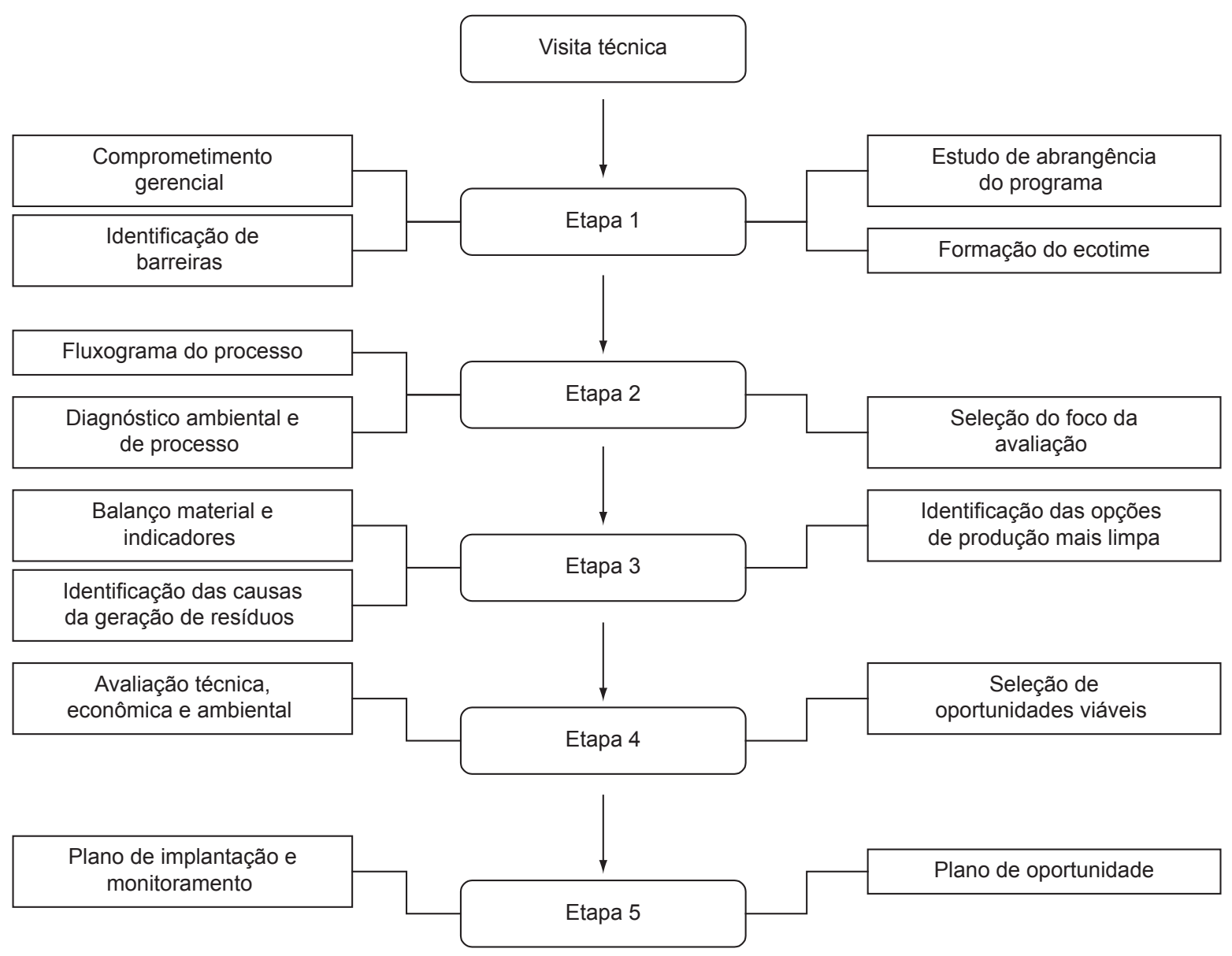

Figura 2. Passos para implementação de um programa de Produção mais Limpa. Fonte: CNTL (2003).

configuração do sistema de operações e direcionar o gerenciamento da organização.

Muitas empresas têm uma visão segmentada, considerando cada setor que as compõem uma unidade separada das demais atividades da organização, levando a conflitos e divergências operacionais que minimizam a resultante dos esforços. A visão sistêmica permite que uma empresa transfira a análise da interação das partes para o todo.

Desta forma, o enfoque sistêmico auxilia o gerenciamento de problemas resultantes das mudanças e a resolução de problemas gerenciais, por meio de uma visão macroscópica da organização. Essa visão também é base da concepção de gestão ambiental, que permite visualizar a organização como um macrossistema que converte entradas em saídas que não agridam ao meio ambiente.

Como programa de gestão ambiental, a Produção Mais Limpa tem essa visão sistêmica, incorporando a idéia de redução da geração de resíduos ao processo produtivo em prol do uso racional dos recursos naturais. A $\mathrm{P}+\mathrm{L}$ poderá auxiliar as empresas do setor terciário na obtenção de oportunidades de crescimento, priorizando a adoção de práticas ambientais e a alocação de capital e recursos para tais práticas, enfatizando a contínua melhoria de seu desempenho ambiental.
Pesquisas desenvolvidas sobre a aplicação do programa de Produção Mais Limpa têm tido como foco a indústria manufatureira. Alguns autores como Kisch (2000), Bartolomeo et al. (2002) e Maxwell e Van der Vorst (2003) acreditam que o maior empecilho na implantação de práticas ambientais nas empresas de serviço é o desconhecimento dos impactos ambientais que estas empresas causam e ainda a necessidade da participação de todos os envolvidos no processo.

Com relação ao programa de Produção Mais Limpa, observa-se que é possível identificar as tecnologias limpas mais adequadas para o processo produtivo, quando se faz uma análise de suas etapas. Entretanto, como Nascimento (2003) afirma, o cronograma sugerido pela UNEP, para implementação do programa de produção mais limpa, é direcionado para plantas industriais e tem sido testado e aplicado há mais de uma década em vários países.

Araújo (2002), apesar de ter desenvolvido seu trabalho em uma empresa considerada prestadora de serviço no setor de construção civil, concentra a implementação do programa nas atividades desenvolvidas por seu back room.

Bass (1995), Boyle (1999) e Maxwell e Van der Vorst (2003) desenvolveram pesquisas em que o foco é a $\mathrm{P}+\mathrm{L}$ 
na indústria manufatureira e, quando procuraram desenvolver algo com relação à prestação de serviço (Maxwell e Van Der Vorst, 2003), focalizaram o back room, assim como Araújo (2002).

Uma organização só poderá adotar o programa $\mathrm{P}+\mathrm{L}$ quando estiver convencida de seus benefícios e das mudanças positivas que podem afetar o sistema de produção do serviço. Então, surge o seguinte questionamento: como seria possível convencer as empresas de serviço a adotarem um programa de produção mais limpa diante das dificuldades impostas pelas características inerentes do setor?

A resposta está na construção de cenários futuros, pela construção de modelos conceituais que dariam uma visão de como seria a prestação do serviço se fosse possível a uma empresa adotar práticas ambientais.

A concepção de Checkland (1972) para solução de problemas focaliza as relações humanas, a construção social das decisões e ações e sua interação com o meio ambiente. A ênfase é dada no processo de formulação dos problemas e suas diversas interpretações. O uso do método de Checkland (1972) visa, a partir da comparação do sistema de produção atual com o modelo conceitual, a definir as ações necessárias para a adoção da $\mathrm{P}+\mathrm{L}$ na empresa. Esse modelo conceitual dá a idéia de como seria o sistema da produção do serviço aliado às práticas da produção mais limpa.

\section{A metodologia de Checkland}

Com a publicação do artigo Towards a systems-based methodology for real-world problem solving em 1972, Checkland apresentou uma metodologia que utiliza a idéia de sistemas para análise e solução de problemas reais, permitindo determinar as modificações necessárias à resolução de problemas, a partir de comparação entre sistemas correntes e o modelo conceitual.

Esta metodologia se baseia na abordagem sistêmica e a reflete, apropriadamente, tratando isoladamente cada aspecto de um problema, para se alcançar o sucesso do todo, podendo ser aplicado em ambientes nos quais a questão principal não é "como fazer" e sim "o que se deve fazer" (Checkland, 1972). A metodologia de Checkland, para a solução de problemas reais, é composta por sete etapas:

1. análise da situação do problema;

2. definição da raiz do sistema relevante;

3. conceitualização;

4. comparação e definição de possíveis mudanças;

5. seleção das mudanças;

6. projeto e implementação; e

7. avaliação.
Martins (1998) afirma que a metodologia de Checkland consiste basicamente na percepção de uma situação dita problemática e desestruturada, em que são levantadas as percepções a respeito da situação para que se tenha uma definição clara da realidade que se deseja transformar, pela identificação de sistemas para análise da situação existente e a construção de um modelo conceitual.

Para Barros Filho (2001), é evidente a preocupação de Checkland em tratar a abordagem sistêmica como um caminho para a análise e solução de problemas reais, inclusive problemas pouco estruturados. Observando-a, tem-se que, em todos os estágios, as percepções, julgamentos sobre a realidade, ações e fatos precisam ser colocados à mesa de discussão e analisados. Isto só será possível na medida em que exista um processo de participação de todos os indivíduos que têm influência sobre a situação em estudo.

O uso da metodologia em questão justifica-se pela necessidade de se obter uma visão abrangente do processo de implantação do programa, de forma a encorajar todos os participantes da prestação do serviço a adotar o programa Produção Mais Limpa $(\mathrm{P}+\mathrm{L})$.

\section{Modelo proposto para a aplicação da metodologia de Checkland na adoção de programas de produção mais limpa em serviços}

Como a intenção aqui é entender como se daria a adoção do programa de $\mathrm{P}+\mathrm{L}$ diante das características da prestação de serviço e não a implementação propriamente dita, utilizou-se a metodologia de Checkland (1972) na fase de visita técnica que é caracterizada pela pré-sensibilização do público alvo (CNTL, 2003), quando os atores envolvidos no processo poderão entender o que é a Produção Mais Limpa.

Para melhor compreensão da metodologia, será apresentado o roteiro de trabalho proposto por Checkland (apud Paladini, 1995).

A diversidade na prestação do serviço dificulta generalizações a respeito de estratégias organizacionais. Entretanto, os elementos que compõem o sistema são os mesmos, diferenciados apenas pelos tipos de processos de cada serviço.

Desta forma, o uso dos componentes de um sistema nesta pesquisa tem como objetivo a comparação da situação real com o modelo conceitual. Isto é, os componentes do sistema (entradas, saídas, processo, etc.) serão indicados como estão na situação atual e será formalizado um modelo conceitual que indique como estes elementos seriam influenciados pela adoção do programa $\mathrm{P}+\mathrm{L}$.

Depois de realizar a comparação entre os modelos reais e conceituais, será exposto o posicionamento da organização com relação à decisão de adotar ou não o programa. O modelo proposto neste trabalho será composto 
por 5 etapas, que seguirão a ordenação representada na Figura 3. Estas etapas serão detalhadas a seguir.

\subsection{Descrição da situação atual}

Para dar início à $1^{a}$ etapa do modelo proposto, é necessário analisar o sistema de produção das empresas prestadoras de serviço. Para isto, decidiu-se considerar a visão de sistemas de Chiavenato (2000), que considera os seguintes elementos que caracterizam um sistema: entradas, saídas, processo, retroalimentação e o ambiente que o delimita. Nesta etapa, propõe-se o diagnóstico dos elementos enumerados acima, a partir da análise de como cada um deles se encontra atualmente, sem a implementação do programa $\mathrm{P}+\mathrm{L}$.

\subsubsection{Entradas}

Em prestação de serviços, os recursos transformados são os mesmos de qualquer sistema de produção: materiais, informações e consumidores. Os materiais podem pertencer diretamente ao cliente ou serem fornecidos pela empresa. Informações ocorrem em todo sistema, seja indiretamente por meio eletrônico ou diretamente entre o cliente e o prestador do serviço.

Os recursos transformadores são aqueles que agem sobre os recursos transformados (Slack et al., 1997). As instalações e os funcionários podem ser considerados esses recursos transformadores que têm grande influência na prestação do serviço. As instalações devem ser direcionadas ao bem-estar do consumidor e o desenvolvimento de pessoal e treinamento de funcionários devem ser focalizados no bom atendimento e na personalização do serviço. Muitas vezes as pessoas são as entradas do sistema, assim, para funcionar, o sistema de prestação de serviços deve interagir com os clientes, sendo estes participantes do processo.

\subsubsection{Saídas}

As saídas do sistema de produção em serviços referemse ao produto acabado, que nesse caso, é o serviço pres- tado. Gerentes do setor têm dificuldade para identificar seus produtos, pois, muitas vezes, a prestação do serviço se confunde com o seu consumo, tornando difícil a caracterização da saída. O produto acabado tem características próprias, mas é a presença do cliente no processo que cria uma preocupação com a utilização total do serviço. O serviço pronto pode ser facilmente sentido pelo cliente, seja com características intrínsecas ou extrínsecas. Todas essas características são notadas pelo cliente e formam a base para sua percepção.

\subsubsection{Processo}

O processo é o conjunto de ações que converte as entradas em saídas. Um aspecto fundamental da prestação de serviços é a compreensão de que o cliente pode ter uma participação ativa no processo, que possui características que nem sempre são determinadas pelas máquinas e as saídas, muitas vezes, não podem ser medidas pelo critério do cumprimento às especificações, como ocorre em manufatura. Como já dito anteriormente, na prestação de serviços, o processo é o produto. As operações não-rotineiras e a simultaneidade entre a produção e o consumo é o que determina o ritmo do processo. Problemas como a definição da capacidade, utilização das instalações e o tempo de espera de clientes são fatores que devem ser considerados.

\subsubsection{Retroalimentação}

É a função no sistema que compara as saídas com um critério ou padrão previamente estabelecido. Todo sistema deve ser continuamente avaliado, devido à necessidade de contínuos ajustes para a reorientação do processo produtivo. Essa retroalimentação é totalmente fundamentada na percepção que o cliente tem do serviço, baseada na experiência com sua totalidade e não apenas no serviço explícito prestado. Como o serviço é prestado na medida em que é consumido, deve-se sempre ter em mente que o sistema deve se adaptar às necessidades dos clientes. A retroalimentação deve ser realizada a partir das reações dos clientes.

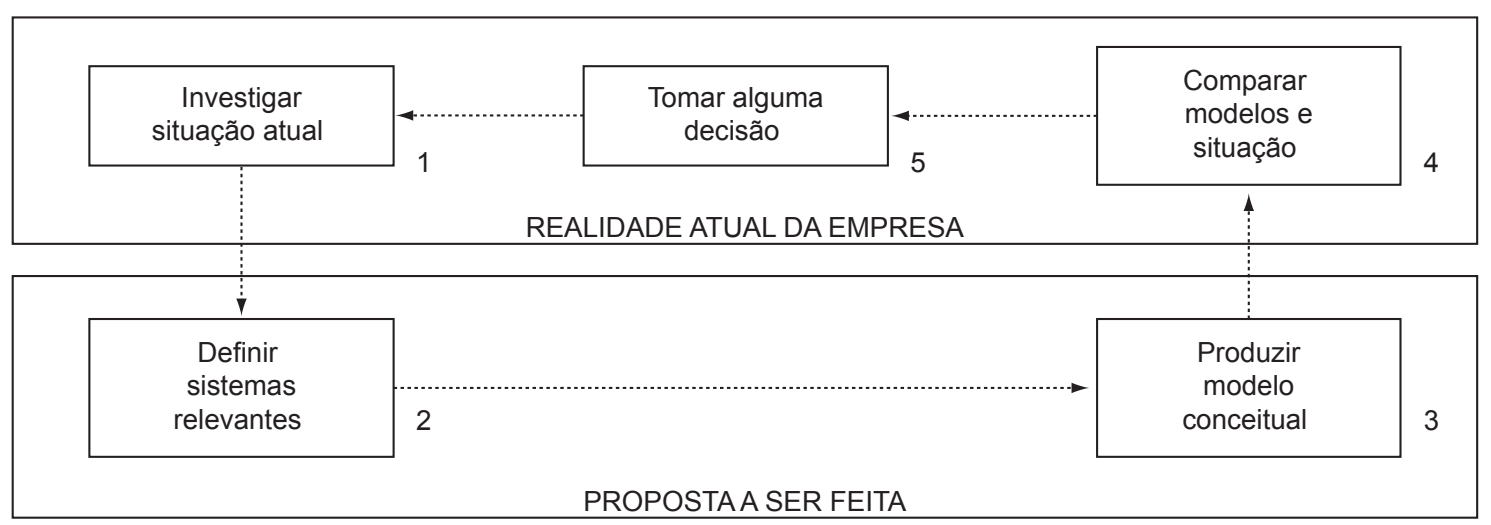

Figura 3. Roteiro de trabalho segundo Checkland. Fonte: Paladini (1995). 


\subsubsection{Ambiente}

É o meio que envolve externamente um sistema. A viabilidade ou sobrevivência de um sistema depende de sua capacidade de se adaptar ao ambiente que o cerca. Esse ambiente serve de fonte de energia, materiais e informações ao sistema. O ambiente no qual está inserida uma empresa de prestação de serviços é dinâmico e o elo entre a organização e seu meio ambiente é determinado pelas características do setor. Este ambiente é tão diversificado que a aplicação de técnicas tradicionais da indústria manufatureira deve sofrer modificações para se adequar ao setor de prestação de serviços.

Outros limites que podem ser impostos ao ambiente do sistema:

- Recursos limitados para investimentos;

- Requisitos legais para operação;

- Legislação ambiental;

- Dificuldade para obtenção de financiamentos;

- Capacitação de pessoal; e

- Freqüentes mudanças no processo para se adequar ao mercado, entre outros.

\subsection{Definição do propósito da implementação do $P+L$}

O propósito principal da adoção do programa é o de auxiliar as empresas prestadoras de serviço na adoção de estratégias ambientais preventivas, que permitam uma melhor organização dos processos, pela inclusão de considerações ambientais na compra de matéria-prima, equipamentos e material de consumo, na minimização de entrada do material e de energia e no planejamento eficiente na distribuição e entrega do serviço acabado.

Um outro propósito da $\mathrm{P}+\mathrm{L}$ é que este considera a variável ambiental em todos os níveis da empresa, relacionando-a com ganhos econômicos para a organização, já que proporciona o processo mais eficiente no emprego de seus insumos, gerando mais produtos e menos resíduos.

\subsection{Conceitualização}

Nesta fase, será descrito o modelo que será usado como referência para a implementação da P + L no sistema de produção de serviços. Assim como foi feita a análise de cada um dos elementos do processo produtivo com a descrição atual do sistema, deverão ser efetuadas análises de cada um dos elementos do processo na prestação de serviços com a adoção da $\mathrm{P}+\mathrm{L}$.

\subsubsection{Entradas}

Com um maior controle das entradas no sistema, será possível também se controlar os resíduos gerados na fonte e, consequientemente, conhecer como o consumidor contribui no lançamento de resíduos e qual sua influência no processo. Para cada entrada poderá ser determinada a forma como ela se acumulará ou deixará o processo produtivo. Isso vale para materiais, informação ou pessoas. Aqui o principal foco deve ser relacionar as entradas reais do sistema atual e indicar quais mudanças podem ser realizadas e quais os benefícios dessas mudanças para a empresa, considerando sempre todos os atores envolvidos.

\subsubsection{Saídas}

O processamento de pessoas deverá ser reestruturado de forma a priorizar as práticas ambientais adequadas aos propósitos do serviço prestado. O serviço final será tão ambientalmente adequado quanto possível e poderá sofrer alterações, desde que haja a aceitação pelos consumidores de um serviço renovado. Essas alterações no serviço podem ser com relação à substituição de materiais que não agridam o meio ambiente, modificação no layout do serviço, uso de materiais recicláveis, entre outros.

É importante mostrar que, mesmo havendo modificações no serviço final, este deverá sempre estar coerente com as metas da empresa. Sendo muito mais do que um conjunto de estratégias organizacionais a serem implementadas, a $\mathrm{P}+\mathrm{L}$ pode auxiliar as empresas na obtenção de serviços limpos e de qualidade.

\subsubsection{Processo}

A geração de resíduos é um claro indicativo de ineficiência do processo. Aqui, essa geração será minimizada, pois cada atividade dentro da prestação do serviço identificará as tecnologias mais adequadas para o seu processo produtivo.

No sistema de produção tradicional, muitas empresas atuam somente na solução de tratamento e geração de resíduos, resultando no aumento dos custos associados ao gerenciamento ambiental. $\mathrm{Na}$ abordagem da $\mathrm{P}+\mathrm{L}$, são privilegiadas as soluções voltadas para a prevenção e minimização, pois nela as empresas de serviço deverão buscar alternativas para o desenvolvimento de um processo ecoeficiente, pela implementação de novas técnicas que permitam a redução permanente dos custos gerais, incorporando ao serviço ganhos ambientais, econômicos e de saúde ocupacional. A adoção de boas práticas ambientais implica a adoção de medidas de procedimento, técnicas, administrativas ou institucionais que uma empresa pode implantar para minimizar os resíduos, efluentes e emissões. Tudo isso em prol da qualidade ambiental do serviço prestado.

Outro ponto importante é a visualização e a definição dos fatores que mais influem na geração de resíduos. Desta forma, se faz necessária a criação de ferramentas que auxiliem a empresa na adoção de práticas ambientais. Muitas dessas ferramentas são voltadas à educação ambiental de consumidores e funcionários, a fim de atin- 
gir aqueles que são atores diretos do processo produtivo.

\subsubsection{Retroalimentação}

Por depender completamente da percepção que o cliente tem do serviço, a avaliação dos resultados de uma organização é, por vezes, subjetiva e muito difícil de ser quantificada. A P $+\mathrm{L}$ prevê um plano de continuidade nas práticas ambientais da empresa que, além de avaliar os resultados obtidos, cria condições para que o programa tenha sua continuidade assegurada.

Desta forma, a avaliação periódica deve verificar se foram atingidos os objetivos de $\mathrm{P}+\mathrm{L}$, ajustando-os quando necessários. Essa retroalimentação de informações em prestação de serviços, antes focalizada somente na percepção que o cliente tem do processo, vem também por meio de dados concretos e quantificáveis, obtidos com planos de monitoramento do sistema. Com esses dados disponíveis, será possível descobrir qual parte do processo pode ser aprimorado de forma a obter melhores resultados das práticas ambientais.

Aqui deve ser explicitado como a retroalimentação do programa pode ser convertida em benefícios para a empresa. As melhorias introduzidas decorrentes do ajustamento do sistema podem resultar no uso mais racional e produtivo de insumos, reduzindo custos de produção, gerando novas oportunidades de negócios e a conquista de novos mercados consumidores.

\subsubsection{Ambiente}

O ambiente em que a organização está inserida é dinâmico e encontra-se inter-relacionado e interdependente com o sistema da empresa. À medida que práticas ambientais sejam inseridas no sistema de produção, o ambiente também será alterado.

Para isso, a avaliação técnica, econômica e ambiental e a seleção das opções de $\mathrm{P}+\mathrm{L}$ que serão adotadas devem considerar o ambiente no qual a empresa se encontra. Assim, será possível conhecer os impactos que as mudanças irão ocasionar em todos os atores envolvidos com a prestação do serviço. As opções de $\mathrm{P}+\mathrm{L}$ selecionadas devem sempre considerar a participação do consumidor no processo de produção do serviço.

É importante mostrar qual é a influência das ações dos funcionários na percepção que o cliente tem do serviço pronto. Se o funcionário está satisfeito e entende que faz parte do sistema, trabalha em busca de melhores resultados para a empresa.

Práticas de $\mathrm{P}+\mathrm{L}$ auxiliam na tomada de decisão das melhores alternativas para um sistema produzir eficientemente, por um custo menor. Alterações no layout e nas instalações de serviços devem ter uma atenção redobrada para que o cliente esteja ciente dos motivos dessas mudanças e participem de forma ativa nas mesmas.
Serviços são criados e consumidos simultaneamente, têm uma demanda variável e são perecíveis e, portanto, não podem ser estocados, o que constitui um grande problema para o gerenciamento de prestação de serviços. Por não haver estoques em prestação de serviços, todo impacto de variação da demanda é transmitido diretamente ao sistema, e a estocabilidade está relacionada com o tempo de espera do cliente. A adoção do programa $\mathrm{P}+\mathrm{L}$ poderá apontar soluções para suavizar a demanda e ajustar a capacidade dos serviços.

Aqui também pode ser apontado como o sistema irá influir positivamente no ambiente, por meio da educação ambiental de funcionários e consumidores, bem como do desenvolvimento de serviços que possam ser produzidos e utilizados de maneira segura por todos.

\subsection{Comparação entre os sistemas e definição das possíveis mudanças}

Nesta etapa é realizada a comparação entre os sistemas atual e conceitual. O objetivo é que, com essa comparação, os empresários entendam quais os benefícios e mudanças ocorridas e se sensibilizem, de forma a adotar o programa de Produção Mais Limpa.

Essa comparação entre os sistemas reais e conceituais pode facilitar a visualização de um cenário futuro, do sistema da prestação do serviço com o programa $\mathrm{P}+\mathrm{L}$, permitindo, desta forma, que seja possível se conhecer os fatores que influenciam na prestação do serviço e os impactos associados a estes componentes.

Nesta visualização de cenários futuros, com relação à adoção das práticas ambientais da $\mathrm{P}+\mathrm{L}$, poderá ocorrer uma mudança na cultura organizacional para que empresas prestadoras de serviço possam se adaptar melhor às suas novas práticas ambientais, visando não somente à sobrevivência, como também a maior participação em um mercado cada vez mais competitivo.

\section{Estudo de caso - Consultório Odontológico}

Para mostrar a viabilidade da proposta deste trabalho, será apresentado um estudo de caso em um consultório odontológico.

A aplicação do modelo proposto no estudo de caso seguiu o roteiro indicado no próprio modelo. Primeiro se fez uma análise geral da empresa, suas características e atividades desenvolvidas, para se conhecer quais impactos ambientais estas empresas podem causar.

Em seguida, realizou-se a descrição da situação atual, a partir da estruturação de cada um dos elementos do sistema da empresa. Nesta etapa, os proprietários procuraram identificar as entradas e saídas, o processo, o ambiente e a retroalimentação do sistema real. 
$\mathrm{Na}$ terceira etapa, foi possível se determinar qual seria o objetivo de se implementar um programa de $\mathrm{P}+\mathrm{L}$ na empresa. Após a definição do propósito da implementação do programa, montou-se o modelo conceitual. Este modelo tentará demonstrar como seriam os componentes do sistema se houvesse um programa de $\mathrm{P}+\mathrm{L}$ na organização.

$\mathrm{Na}$ etapa final, é realizada a comparação entre o sistema real e o modelo conceitual. O objetivo é que, com essa comparação, os empresários entendam quais os benefícios e mudanças ocorridas e se sensibilizem, de forma a adotar o programa de Produção Mais Limpa.

Sabe-se que deve haver a participação de todos na adoção do programa, no entanto, na aplicação do modelo aqui proposto, houve apenas a participação dos sócios da empresa. Isto se deve principalmente ao fato de que a aplicação do modelo proposto neste trabalho se dá na primeira etapa do programa de $\mathrm{P}+\mathrm{L}$ em que é realizada a visita técnica. Como o manual de Implementação de Programas de Produção Mais Limpa (CNTL, 2003) indica, esta etapa é realizada com o público-alvo, isto é, empresários e gerentes. Por este motivo, o modelo aqui proposto foi aplicado considerando a percepção deles com relação à $\mathrm{P}+\mathrm{L}$.

O estudo de caso foi realizado em um consultório odontológico, formado por três dentistas e um auxiliar, que desempenha também a atividade de atendimento ao público. Esta empresa está localizada na área norte da Região Metropolitana do Recife e cada dentista atende em média 30 pacientes por semana. Por possuir apenas uma sala equipada para tratamentos odontológicos, as três sócias dividem o horário de atendimento, que é de segunda a sábado das 9 às 19 horas. $\mathrm{O}$ tempo de espera por parte dos pacientes para serem atendidos é em média de 15 minutos.

No consultório, a variedade de serviços é diversificada, entretanto existe certa rotina em cada atividade. A interação com os clientes é muito grande e o consultório não é estruturado como empresa, mas como sociedade, isto é, as sócias não são remuneradas simplesmente com salários, mas com cota de receita da empresa, após terem sido pagos o salário do auxiliar e as despesas gerais.

\subsection{Impactos ambientais identificados}

O amálgama dental é um dos materiais restauradores mais utilizados nas clínicas odontológicas. Um de seus componentes é o mercúrio, cuja utilização tem sofrido algumas restrições no decorrer dos tempos. O processo de contaminação do meio ambiente ocorre por descuido na utilização deste metal.

O mercúrio promove a contaminação das nuvens. As nuvens contaminadas promovem, a longa distância, chuvas tóxicas. Assim, as águas contaminadas depositam-se no solo, nos rios, lagos e oceanos.

Sabe-se que, durante o preparo do amálgama para realizar uma restauração, a sobra é de cerca de $30 \%$ do que é amalgamado. Esta sobra é resultante do excesso manipulado, bem como das raspas produzidas pela escultura do amálgama.

Outro ponto importante a se considerar diz respeito ao descarte e disposição final de materiais de corte, como bisturi, agulha e tubos de anestésicos.

\subsection{Descrição da situação atual}

Nesta fase da metodologia, as dentistas procuraram visualizar como se dava a prestação do serviço, para poder descrever cada um dos elementos do sistema. Desta forma, foram identificadas as seguintes entradas: pacientes, substâncias químicas, material médico-hospitalar, medicamentos e equipamentos hospitalares. As substâncias químicas dependem do serviço que será prestado e do histórico de alergias e reações do paciente.

A principal saída é o paciente com meio bucal adequado. Também foram identificados objetos perfurantes ou cortantes e substâncias químicas, como glutaraldeído e amálgama odontológico.

$\mathrm{O}$ processo funciona da seguinte maneira: o paciente solicita o serviço odontológico; a dentista faz a anaminese, que consiste em uma seqüência de interrogações sobre dados pessoais e familiares, que dão às dentistas informações importantes acerca do histórico do paciente; é realizado um exame extra-oral e intra-oral para identificação do problema; realiza-se o diagnóstico; determinase o tratamento; e o serviço é finalizado com o prognóstico do paciente.

A retroalimentação é realizada por meio do acompanhamento do paciente, a cada 6 meses. As sócias afirmam que não existe um procedimento para se medir a satisfação do cliente com relação à prestação do serviço.

Para as sócias, o principal fator que influencia o ambiente é a relação com o paciente. $\mathrm{O}$ mal-estar que o paciente experimenta diante de uma situação tensa frente ao dentista e o medo então gerado pela situação pode tornar a relação dentista/paciente muito difícil. Lidar com as emoções dentro do consultório odontológico é o principal meio para profissionais da área odontológica entrarem em contato com a comunidade.

\subsection{Definição do propósito da implementação do $P+L$}

Para as sócias, esta etapa da metodologia estava bem clara, já que existia uma compreensão dos impactos ambientais na prestação do serviço odontológico.

As sócias têm uma grande preocupação com a disposição final dos resíduos, principalmente resíduos químicos e materiais de corte. Então, a adoção da $\mathrm{P}+\mathrm{L}$ teria como principal objetivo o controle dessas saídas, de forma a evitar a contaminação do meio ambiente e, conseqüentemente, custos por multas e punições devido à disposição inadequada desses resíduos. 


\subsection{Conceitualização}

Para se estruturar o modelo conceitual, as proprietárias tinham em mãos alguns artigos relacionados com a adoção de práticas ambientais em consultórios odontológicos.

Assim, as entradas do sistema com a Produção Mais Limpa seriam compostas da seguinte forma: pacientes; substâncias químicas devidamente manipuladas; material médico-hospitalar que não agridam o meio ambiente; e medicamentos e equipamentos hospitalares que auxiliem na redução do consumo de energia.

As saídas seriam: paciente com meio bucal adequado e conhecedor das práticas ambientais do consultório; descarte e disposição final correta de objetos perfurantes ou cortantes, seguindo orientações da Vigilância Sanitária e órgãos ambientais; e substâncias químicas, com armazenamento e disposição final ecologicamente corretos.

Haverá um controle maior no processo no que diz respeito à utilização das substâncias químicas, desde a anaminese até o tratamento do paciente. Também será necessária a troca de alguns equipamentos que consomem muita energia, e o treinamento das dentistas e do auxiliar para o correto manuseio e disposição final de materiais perfuro-cortantes.

Além do acompanhamento do paciente, poderá ser possível obter informações sobre o bom funcionamento do programa $\mathrm{P}+\mathrm{L}$ pela redução do consumo de energia elétrica e pelo atendimento de requisitos ambientais.

Com a adoção do P $+\mathrm{L}$, será possível se conhecer os impactos ambientais associados à atividade odontológica e tentar preveni-los de forma a não afetar os atores ligados direta ou indiretamente ao processo.

Desta forma, haverá uma mudança significativa nas relações com os clientes, comunidade e órgãos responsáveis, já que haverá uma melhor adequação aos padrões ambientais e um comprometimento maior do consultório com o uso racional dos recursos naturais.

\subsection{Comparação e definição das possíveis mudanças}

Proteger o meio ambiente pela recuperação de mercúrio contido nos resíduos de amálgama dental lançados no ambiente, minimizando os riscos à saúde dos seres humanos, é o principal fator de preocupação das dentistas.

Com a adoção de práticas de Produção Mais Limpa é possível reunir informações sobre a quantidade de resíduos depositados no meio ambiente. Analisando a situação atual com o modelo conceitual, as dentistas identificaram algumas ações que podem auxiliar na solução do problema em questão.

A primeira ação que foi possível identificar é que o uso da menor relação possível de mercúrio na liga, não traz prejuízo ao tratamento do paciente e ainda diminui o risco da disposição final da amálgama.
Outra ação identificada é com relação à coleta dos resíduos de amálgama, que pode ser feita em recipiente dotado de boca larga, material inquebrável e que possa ser hermeticamente fechado. O resíduo de amálgama deve estar isento de algodões, gazes, palitos, lâminas de matriz de aço e quaisquer outros tipos de contaminante. Para isso, deve haver uma orientação para armazenar os resíduos de amálgama de tal forma que sua recuperação seja menos dispendiosa e a mais rápida possível.

Depois desta armazenagem, é possível buscar parcerias com outras instituições odontológicas e Serviços Municipais de Saúde, visando à recuperação do mercúrio e da prata dos resíduos odontológicos. Essas mesmas precauções podem ser realizadas com outros resíduos químicos da atividade odontológica.

Com relação aos materiais perfuro-cortantes foi identificada a necessidade de melhoria na sua disposição final. Para isso, se faz necessário o procedimento determinado pela Secretaria de Saúde (Programa de Controle de Infecção de Serviços de Saúde - Ministério da Saúde), que determina que esses materiais sejam depositados em bombonas de plásticos ou papelão, lacradas corretamente, para posterior descarte. Esse descarte pode ser realizado por um órgão competente ou por empresas privadas que realizam esse tipo de serviço.

Outra oportunidade de melhoria encontrada foi a de economia de energia. O consultório, mesmo quando não estava sendo utilizado por alguma das dentistas, era mantido pronto para funcionamento, com todas as luzes e equipamentos ligados. Isso ocorria, porque se acredita que o paciente se sente mais à vontade e confia mais no serviço, quando existe certa prontidão no atendimento.

Entretanto, diante do simples desligamento das luzes e de alguns equipamentos que poderiam ser ligados ou desligados sem prejuízo ao atendimento ou ao próprio maquinário, foi possível verificar de pronto um decréscimo no consumo de energia do consultório. Todos os pacientes que foram atendidos receberam informações sobre o novo posicionamento das sócias com relação às práticas ambientais e demonstraram estarem satisfeitos com as novas práticas no consultório.

\subsection{Posição da empresa quanto à implantação da $P+L$}

No estudo de caso, pode-se perceber que existe uma falta de conhecimento e conscientização das sócias com relação à disposição final de resíduos químicos e perfurocortantes. Com as oportunidades de P + L identificadas, foi possível conhecer formas menos prejudiciais ao meio ambiente para o descarte deste material.

A princípio, tinha-se uma noção errônea sobre a adoção de práticas ambientais em serviços de saúde. Para as sócias, os custos associados eram maiores que os benefícios que o consultório poderia obter com a adoção da 
$\mathrm{P}+\mathrm{L}$. Entretanto, diante da comparação entre os sistemas da prestação do serviço, foi possível identificar as falhas e compreender como seria possível oferecer um serviço de qualidade e que fosse ambientalmente correto.

Diante dos resultados imediatos alcançados com a redução do consumo de energia e das práticas corretas da disposição final de resíduos, as dentistas se mostraram dispostas à adoção da $\mathrm{P}+\mathrm{L}$ no consultório, desde que a implementação do programa não afete a prestação do serviço odontológico.

\section{Considerações finais}

Devido ao sucesso de implementação do programa em empresas industriais, procurou-se neste trabalho verificar qual o principal obstáculo para implementação da $\mathrm{P}+\mathrm{L}$ nas empresas prestadoras de serviço. Diante da análise de alguns artigos, observou-se que a maior dificuldade, não só de implementar a $\mathrm{P}+\mathrm{L}$, mas qualquer outro programa ambiental, está no fato de que estas empresas não conhecem os impactos que causam ao meio ambiente e acreditam que acidentes ambientais sejam problemas exclusivos da indústria manufatureira.

O principal questionamento está relacionado ao que é necessário para que empresas prestadoras de serviço adotassem o programa de $\mathrm{P}+\mathrm{L}$, se não sabem como se daria a implementação. A resposta estaria na estruturação de um modelo conceitual, que permitisse aos empresários do setor compreender o processo de adoção do programa, as mudanças que ocorreriam e os benefícios alcançados com a implementação da $\mathrm{P}+\mathrm{L}$ na prestação do serviço.

Com a análise da bibliografia existente, verificou-se a inexistência de metodologias que auxiliem as empresas de serviço na implementação de programas ambientais. Como resultado, este artigo propõe a adoção da metodologia de Checkland (1972), que se adapta a esse propósito, já que possibilita identificar e estruturar situações problemáticas caracterizadas por desacordos e incertezas quanto à natureza do contexto de um problema, neste caso, como se daria a implementação do programa $\mathrm{P}+\mathrm{L}$ em empresas de serviço. Isto gerou o modelo de Implementação do Programa a Produção Mais Limpa em Empresas Prestadoras de Serviço.

Algumas conclusões foram alcançadas ao término deste trabalho. Primeiramente, a adoção da $\mathrm{P}+\mathrm{L}$ em empresas prestadoras de serviço é possível, desde que sejam consideradas suas peculiaridades para definir a melhor forma de se implementar o programa. O modelo proposto se mostrou prático e de fácil compreensão, provavelmente devido ao uso da metodologia de Checkland, que pode auxiliar os gestores na visualização de um cenário futuro, do sistema da prestação do serviço com o programa $\mathrm{P}+\mathrm{L}$.

Com relação ao Estudo de Caso, a empresa participante está disposta a implementar o programa de Produção Mais Limpa, desde que isto não lhe acarrete custos adicionais. As pessoas entrevistadas acreditam que se houvesse uma maior divulgação sobre o programa $\mathrm{P}+\mathrm{L}$ e os benefícios alcançados com sua adoção, os empresários do setor de prestação de serviços ficariam mais receptivos com relação às práticas ambientais.

Por fim, foi possível compreender que, com a adoção da $\mathrm{P}+\mathrm{L}$, as empresas prestadoras de serviço poderão conhecer os aspectos e os impactos ambientais de seus processos, fazendo com que seja possível identificar oportunidades de redução de custos, promovendo o crescimento da organização.

\section{Agradecimentos}

As autoras agradecem o apoio recebido para concretização deste trabalho do Conselho Nacional de Desenvolvimento Científico e Tecnológico (CNPq), entidade governamental brasileira promotora do desenvolvimento científico e tecnológico.

\section{Referências Bibliográficas}

ARAÚJO, A. F. A aplicação da Metodologia de Produção Mais Limpa: Estudo em uma empresa da construção civil. 2002. 121 f. Dissertação (Mestrado em Engenharia de Produção) - Programa de Pós-Graduação em Engenharia de Produção, Universidade Federal de Santa Catarina, Florianópolis, 2002.

BARROS FILHO, E. A. Um modelo para Integração dos sistemas de gestão. 2001. 57 f. Dissertação (Mestrado em Engenharia de Produção) - Centro de Tecnologia e Geociências, Universidade Federal de Pernambuco, Recife, 2001.
BARTOLOMEO, M. et al. Eco-efficient producer services-what are they, how do they benefit customers and the environment and how likely are they to develop and be extensively utilised? Journal of Cleaner Production, London, v. 11, n. 8, p. 829-837, dez. 2003.

BASS, L. W. Cleaner Pruduction: beyond projects. Journal of Cleaner Production, London, n. 1-2, p. 55-59, 1995.

BOYLE, C. Cleaner production in New Zealand. Journal of Cleaner Production, London, v. 7, n. 1, p. 59-67, fev. 1999. 
CENTRO NACIONAL DE TECNOLOGIAS LIMPAS - CNTL. As Cinco Fases da Produção Mais Limpa. Apostila. Porto Alegre, 2002. 91 p.

Implementação de Programas de produção Mais Limpa. Apostila. Porto Alegre, 2003. 46 p.

Disponível em: <http://www.rs.senai.br/ cntl/>.Acesso em: 20 jan. 2004.

CHECKLAND, P. B. Towards a systems-based methodology for real-world problem solving. System Engineering, v. 3, n. 2, winter, 1972 .

CHIAVENATO, I. Introdução à Teoria Geral da Administração. $6^{\circ}$ ed. Rio de Janeiro: Campus, 2000. 700 p.

GIANESI, I. G. N.; CORRÊA, H. L. Administração Estratégica de Serviços. São Paulo: Atlas, 1996. 234 p.

$\mathrm{KISCH}, \mathrm{P}$. Preventative Environmental Strategies in the Service Sector. 2000. 208 f. Doctoral Dissertation. International Institute for Industrial Environmental Economics, Lund University, Lund - Sweden, 2000.

MARTINS, F. M. Aplicação de metodologia multicritério de apoio à decisão na avaliação de políticas de gerenciamento em uma empresa orizícola. 1996. Dissertação (Mestrado em Engenharia de Produção) - Programa de Pós-Graduação em Engenharia de Produção, Universidade Federal de Santa Catarina, Florianópolis, 1998.

MAXWELL, D.; VAN DER VORST, R. - Developing sustainable products and services. Journal of Cleaner Production, London, v. 11, n. 8, p. 883-895, dez. 2003.
NASCIMENTO, C. A. M. Em busca da ecoeficiência. Disponível em: <www.rs.senai.br>. Acesso em: 27 out. 2003.

NISSEN, U. A methodology for the development of cleaner production: the ideal-eco-product approach. Journal of Cleaner Production. London, v. 3, n. 1-2, p. 83-87, 1995.

OLIVEIRA FILHO, F. A. A aplicação do conceito de produção limpa: estudo em uma empresa metalúrgica do setor de transformação do alumínio. 2001. 174f. Tese (Doutorado em Engenharia de Produção) - Programa de Pós-Graduação em Engenharia de Produção, Universidade Federal de Santa Catarina, Florianópolis, 2001.

PALADINI, E. P. Gestão da Qualidade no Processo. São Paulo: Editora Atlas, 1995. 400 p.

PNUMA - Programa das Nações Unidas para o Meio Ambiente. Cleaner Production for Worldwide. PNUMA, 1993.

SLACK, N. et al. Administração da Produção. São Paulo: Editora Atlas, 1997. 748 p.

TÉBOUL, J. A Era dos Serviços. Rio de Janeiro: Qualitymark, 1999. 312 p.

UNEP (UNITED NATIONS ENVIRONMENTAL PROGRAMME). Disponível em: < www.uneptie.org > . Acesso em: 14 mar. 2003.

ZWETSLOOT, G. I. J. M.; GEYER, A. The essential elements for successful cleaner production programmes. Journal of Cleaner Production. London, v. 4, n. 1, p. 29-39, 1996.

\title{
CLEANER PRODUCTION IMPLEMENTATION IN SERVICES USING CHECKLAND'S METHODOLOGY
}

\begin{abstract}
The Cleaner Production program has been applied successfully in the manufacturing industry. However, this instrument is far from service company's adoption. The main contribution of this thesis is to characterize the development and application of the Cleaner Production program in Services using Checkland Methodology for structuring problems. The main objective of this methodology is make a comparison between the real system (the way the company is today) and the conceptual system (the way the company would work if it adopted the Cleaner Production) as it traces the changing pictures and help managers to decide on adopting this program or not. The aim of the presented Case Studies is to show how the model is applied in service companies.
\end{abstract}

Keywords: cleaner production, sustainable development, environmental management system, sevices companies. 